\title{
Effect of Oil Heat Treatment on Chemical Constituents of Semantan Bamboo (Gigantochloa scortechinii Gamble)
}

\author{
Rafidah Salim \& Razak Wahab \\ School of International Tropical Forestry \\ University Malaysia Sabah \\ Locked Bag No. 2073, 88999, Kota Kinabalu, Sabah, Malaysia \\ Tel: 60-88-320-000-8781Ｅ-mail: rafidahs@ums.edu.my \\ Zaidon Ashaari \\ Faculty of Forestry \\ Universiti Putra Malaysia \\ 43400 Serdang, Selangor, Malaysia
}

Tel: 60-3-8946-0000-7169Ｅ-mail: zaidon@putra.upm.edu.my

\begin{abstract}
Effect of oil heat treatment on chemical constituents of 3 years old Gigantochloa scortechinii Gamble bamboo was investigated. The bamboo splits within epidermis were heat-treated using crude palm oil at temperature $140^{\circ} \mathrm{C}, 180^{\circ} \mathrm{C}$ and $220^{\circ} \mathrm{C}$ for duration 30 and $60 \mathrm{~min}$. After removed the epidermis, the samples were then grind to pass a BS 40-mesh sieve and retained on a BS 60-mesh sieve. The sawdust was air dried for several days before conducted to chemical analyses (cellulose, hemicellulose and lignin) based on TAPPI Standard Methods. The colorimetric method devised by Humprey and Kelly (1960) was adapted to analysis starch in bamboo. Reading was obtained through Baush Lomb UV Spectrophotometer at $650 \mu \mathrm{m}$ calculated by standard reference using A.R. potato starch. Control was used as comparison for each type of test conducted. There was no significant different between control and condition at $140^{\circ} \mathrm{C}$ for $60 \mathrm{~min}(81.4 \%)$ of holocellulose content. The value was decreased by 2.1 to $10.7 \%(79.7$ to $72.7 \%)$ after heating at 180 to $220^{\circ} \mathrm{C}$ for 30 to $60 \mathrm{~min}$. The hemicellulose content of bamboo was ranged 24.1 to $27.8 \%$ after heating at $140-220^{\circ} \mathrm{C}$ for 30 to $60 \mathrm{~min}$. The cellulose content of heat-treated bamboo was ranged 47.4 to $55.2 \%$ after reduced about 2 to $14 \%$. Lignin content increased about $16 \%(26 \%)$ at $220^{\circ} \mathrm{C} / 60 \mathrm{~min}$ after reduced approximately 1 to $5 \%$ at 140 to $180^{\circ} \mathrm{C}$ for 30 to $60 \mathrm{~min}$. Starch content was largely reduced about 2 to $54 \%$ (4 to $1.9 \%$ ) at 140 to $180^{\circ} \mathrm{C}$ for 30 to $60 \mathrm{~min}$ of treatment. The results indicated that degradation of cellulose and hemicellulose of heat-treated bamboo was attributed to plasticization of lignin during heating in the same time hydrolysed the starch content.
\end{abstract}

Keywords: Bamboo, Oil heat treatment, Chemical constituents

\section{Introduction}

Bamboo is regarded as eco-friendly, which grows and matures quickly has potential to be used as an alternative material for wood. The world is loosing its resource of wood due to higher demand and to recover the resources will take 15 to 20 years. Many researches agreed that the suitable age of the bamboo used is 3 to 4 years old (Thammicha, 1989; Abd. Latif et al., 1990; Jamaluddin, 1999).

However, bamboo is easily susceptible to fungi or insect attack during utilization. The properties will deteriorate rapidly if the material is not treated with preservatives (Liese, 1985). Low durability is a major reason for the poor acceptance of bamboo as a building material. They are often considered as a short-term material suitable only for temporary uses (Liese and Kumar, 2003). The used of preservative in bamboo has been recognized as necessary and important for utilization in furniture and construction purposes.

Recent work on the heat treatment process of timber to prepare what is currently called torrefied wood in France, plato wood in the Netherlands and retified wood in the USA has shown that such types of processes can improve the performance of timber in several aspects (Ruyter, 1989). Foremost advantages of the wood treated improve its resistance to fungal decay (Ruyter, 1989 and van Zuylen, 1995) without the need to use any chemical solutions with consequent environmental advantages, water repellency and improve dimensional stability to moisture variations. 
Oil heat treatment is another alternative way in treating bamboo without use of preservatives. This process is considered as eco-friendly treatment. Leithoff and Peek, 1997 reported that only temperature above $170^{\circ} \mathrm{C}$ was effective to enhance durability of bamboo however, Boonstra and Tjeerdsma, 2005 indicated that chemical composition was modified at this condition. In this study modification of the polymeric of bamboo constituents after oil heat treatment at 140 to $220^{\circ} \mathrm{C}$ for 30 to $60 \mathrm{~min}$ was investigated. The aims of this study were:-

- To analyze the chemical properties of heat-treated bamboo

- To investigate the reaction mechanism occurring during heating at each condition applied.

\section{Material and methods}

\subsection{Preparation of Bamboo Samples}

Bamboo culms of 3 years old were extracted from randomly selected clumps in Nami, Kedah in Malaysia. The culms were cut and splitted before conditioned at $20 \pm^{\circ} \mathrm{C}$ and $65 \mathrm{RH}$ until constant weight. The sample were then subjected to heating at varies temperature and time.

\subsubsection{Heat treatment Process}

Palm oil which the boiling point of $320^{\circ} \mathrm{C}$ fulfilled $3 / 4$ tank. Split bamboo samples were immersed in crude palm oils with original temperature in metallic cage of stainless steel tank. Temperature was rise gradually controlled by digital controller. Three electric heaters were generated heat from electricity power sources. Data logger connected to thermocouple where four and three channels placed inside and outside (oil) of the bamboo samples. Data were recorded every $5-10^{\circ} \mathrm{C}$ interval. In this experiment, temperature was applied at $140^{\circ} \mathrm{C}, 180^{\circ} \mathrm{C}$ and $220^{\circ} \mathrm{C}$ with duration 30 and 60 minutes. Bamboo samples were taken out at reached temperature. Residual oil on bamboo surface was removed by wiping with cloth to avoid absorbance into bamboo samples.

\subsection{Chemical Analysis of Bamboo}

\subsubsection{Preparation of sawdust}

A small of bamboo sample (20 mm x 20mm x thickness) was cut from the heat-treated bamboo. The epidermis of bamboo was removed before grind to pass a BS 40-mesh sieve and retained on a BS 60-mesh sieve. The sawdust was air dried for several days until it reached the constant weight prior to chemical analysis. The procedure was referred from TAPPI Standard.

\subsubsection{Moisture Content of Sawdust}

A small weighing bottle previously cleaned and dried in an oven was weighed on an analytical balance to 0.01 g. $2.0 \mathrm{~g}$ air dry sawdust was placed on the weighing bottle and reweigh to $0.01 \mathrm{~g}$. The sample was dried in the oven at $105^{\circ} \mathrm{C}$ for three hours with the cover off. Then the bottle was removed and placed in the desiccator for 15 minutes to cool, (observing the proper precautions concerning the desiccators lid and the handling of the bottle by using tongs) before weighing. The moisture content on the basis of the air-dry weight was calculated by dividing the loss in weight by air-dry weight.

\subsubsection{Determination of Holocellulose content}

$2 \mathrm{~g}$ of air dried extractive-free sawdust was weighed accurately. The sawdust was transferred quantitatively to a $250 \mathrm{ml}$ conical flask. $100 \mathrm{ml}$ water, 1.5 sodium chloride and $5 \mathrm{ml}$ of $10 \%$ acetic acid were added and the flask was placed in a water bath maintained at $70^{\circ} \mathrm{C}$, swirling the content of the flask at least once every five minutes. The flask was kept closed with a small, inverted Erlenmeyer flask.

$5 \mathrm{ml}$ of $10 \%$ acetic acid was added after 30 minutes. 1.5 sodium chloride was added after further 30 minutes. Alternative acetic acid and sodium chloride at 30 minutes were continued, after last addition of sodium chloride. The mixture was heated for 30 minutes after last addition of sodium chloride. Residue should be white and retain woody structure. The suspension was cooled in an ice bath.

Residue was filtered into a weighed fruited glass crucible (medium or coarse porosity) and washed with iced distilled water and finally washed with acetone. The residue was air-dried (allowed the residue to strand in the open laboratory for a day or two until it is free of acetone). Covered it with a perforated aluminium foil. The sample was transferred to a desiccator and weighed at daily intervals until the sample reached constant weight. The moisture content was determined on a $0.5 \mathrm{~g}$ sample which is afterward.

\subsubsection{Determination of Cellulose content}

Air-dried holocellulose was used. The experiment was carried out in a water bath at $20^{\circ} \mathrm{C}$. About $2 \mathrm{~g}$ of sawdust were weighed out accurately and transferred into a $20 \mathrm{ml}$ beaker than placed in a water bath at $20^{\circ} \mathrm{C} .15 \mathrm{ml}$ of $17.5 \mathrm{NaOH}$ was added and macerated gently with a flattened glass with rod for 1 minute. $10 \mathrm{ml}$ more $\mathrm{NaOH}$ was added and the solution was mixed for 45 seconds. Then, $10 \mathrm{ml}$ more was added and mixed for 15 seconds so that at the end of 2 
minutes $35 \mathrm{ml}$ of the $\mathrm{NaOH}$ have been added. The mixture was stirred and allowed to stand for another 3 minutes. After 3 minutes, another 10 mililitre $\mathrm{NaOH}$ was added and mixed with stirring rod in the solution for every 2.5 minutes for 4 times.

The beaker was covered with watch glass and the mixture was left in the water bath for 30 minutes more. Then $100 \mathrm{ml}$ of distilled water were added at $20^{\circ} \mathrm{C}$ quickly and thoroughly mixed and left the diluted mixture in the water bath for further 40 minutes. The mixture was filtered into a weighed fruited glass crucible (coarse porosity). If suspended fibers are noticed in the filtered, pass it through the cellulose mat again to clarify it. The beaker was rinsed and residue $25 \mathrm{ml}$ of $8.3 \mathrm{NaOH}$ solutions at $20^{\circ} \mathrm{C}$ and quantitatively transfer all the fiber to the crucible. During the filtration, the cellulose pad covered was always kept with solution to prevent drawing air through the pad.

The pad was washed with $650 \mathrm{ml}$ distilled water at $20^{\circ} \mathrm{C}$. The suction tube was disconnected, filled the crucible with $2 \mathrm{~N}$ acetic acid at $20^{\circ} \mathrm{C}$ and the residue was allowed to soap for 5 minutes. Suction was reapplied to remove acetic acid. The residue was washed with the distilled water until it free of acid as indicated by the litmus paper. The bottom and side of the side of the crucible were wiped out with a dry towel and placed in the oven at $50^{\circ} \mathrm{C}$, dried to constant weight, then cooled and weighed. Alpha cellulose was calculated as a percentage based on oven dry sample.

\subsubsection{Determination of Lignin content}

The procedure was referred from TAPPI Standard T 222 os-74. $1 \mathrm{~g}$ of air dried extractive free sawdust was weighed out accurately in weighing bottle and transferred in a $50 \mathrm{ml}$ beaker. $10 \mathrm{ml}$ of $72 \%$ sulphuric acid were added carefully with a pipetted and the mixture was stirred with a small glass rod (which is left in beaker). The mixture was left quantitatively with a wash bottle (water) to a $500 \mathrm{ml}$ round-bottle flask and diluted with water until the final volume is $300 \mathrm{ml}$. While the solution was refluxing (boiled under reflex for 3 hour), a crucible was oven dried (fine or medium porosity) for 1 hour at $110^{\circ} \mathrm{C}$, then allowed to cooled in a desiccator $(15$ minutes and accurately weighed. When the refluxing was completed, the insoluble lignin was recovered by filtration through the crucible after allowing the lignin to settle to facilitate filtration. The lignin free was washed from act with $250 \mathrm{ml}$ of hot distilled water. The crucible containing the lignin was dried at $110^{\circ} \mathrm{C}$ for 1 hour, cooled in a desiccator (15 minutes) and weighed. Lignin content was reported as reported as percentage by weight of the dried sample.

\subsubsection{Starch Content}

The method devised by Humprey and Kelly (1960) was adopted to determine the starch content through the basic reaction of the amylose in bamboo starch with iodine

\subsubsection{Preparation of powder}

Bamboo samples were first ground in order to pass a 200 mesh sieved and triplicate samples of $0.4 \mathrm{~g}$ each were dried for 72 hours in desiccator oven containing concentrated sulphuric acid and added with 4-7 $\mathrm{ml}$ of $7.2 \mathrm{M}$ perchloric acid in a $50 \mathrm{ml}$ beaker. Reactions were allowed to continue for 10 minutes with occasional stirring. The contents were then transferred into a $50 \mathrm{ml}$ volumetric flask and made up to the volume with distilled water.

After centrifuging, $10 \mathrm{ml}$ aliquots were placed in a $50 \mathrm{ml}$ volumetric flask together with a drop of phenolphthalein and made alkaline with $2 \mathrm{~N}$ Sodium hydroxide. Then $2 \mathrm{~N}$ acetic acid was added of $2.5 \mathrm{ml}$ acetic acid, $1.5 \mathrm{ml}$ of $10 \%$ weight over volume potassium iodine and $5 \mathrm{ml} 0.01 \mathrm{~N}$ Potassium iodide. Color was allowed to develop for 15 minutes before the absorption (Baush Lomb UV Spectrophotometer) at $650 \mu \mathrm{m}$ was measured. A blank was prepared without starch aliquot. The starch content was then calculated by applying the formula:

Starch $=\underline{0.36778 \times(\text { E. reading }+0.008)} \times \underline{50} \times 100$

$$
\text { Oven-dry weight of sample (g) } \quad 10
$$

Where,

$$
\text { E reading }=\text { differences of absorption between sample and blank }
$$

\subsection{Statistical Analysis}

The statistical analysis was carried out using the statistical analysis software (SAS). All data were analyzed using one-way analysis of variance (ANOVA) and the mean value was separated using Least Significant Difference (LSD) to determine the differences between treatment levels.

\section{Result and Discussion}

\subsection{Effects of heating on chemical properties of G. scortechinii}

The mean contents of holocellulose, hemicellulose, cellulose, lignin and starch in the treated and untreated Gigantochloa scortechinii after heating treatment are exhibited in Table 3.1. The hemicellulose content was calculated based on the deducted from holocellulose to alpha-cellulose. 


\subsubsection{Holocellulose content}

The results in Table 3.1 show that holocellulose content in the treated bamboo significantly reduced when they were treated at $220^{\circ} \mathrm{C} / 60 \mathrm{~min}$. The chemical reduced by $10.7 \%$ from $81.4 \%$ (untreated) to $72.7 \%$. Even though they was slight reduction for the those treated at higher temperature, the reduction however, was not significant. The holocellulose content were in the range of $77 \%$ to $81 \%$. The reduction of holocellulose at higher temperature (above $180^{\circ} \mathrm{C}$ ) was due the depolymerisation of the hemicelluloses and some degradation of the cellulose during heating.

In a previous study on heat treatment of Scots pine, Boonstra and Tjeerdsma, (2005) also found the similar results where the holocellulose content of the wood decreased from $79.7 \%$ to $63.3 \%$ when it was heated at $180^{\circ} \mathrm{C}$.

Bamboo holocellulose contains all carbohydrates in bamboo also the sum of the cellulose and hemicellulose. The reduction of holocellulose was possibly attributed to the degradation of hemicelluloses and cellulose.

\subsubsection{Hemicellulose content}

There is no specific trend of hemicellulose content of bamboo. Even though there was a reduction by $8 \%$ of the chemical when treat at $180^{\circ} \mathrm{C} / 60 \mathrm{~min}$ and above, the reduction was not significant. The hemicellulose content for treated and untreated bamboo were in the range $24-28 \%$.

During heating, acetic acid is formed from aceylated hemicelluloses by hydrolysis. The released acid serves as a catalyst in the hydrolysis of hemicelluloses to soluble sugars. In addition, the acetic acid that has formed depolymerises the cellulose microfibrils in the amorphous area. The acid hydrolyses the bonds joining the units of glucose, breaking cellulose into shorter chains. However, the breaking of a hemicellulose chain does not reduce as much the strength of the bamboo as breaking of cellulose chains would do.

Tjeerdsma and Militz (2005), found hemicellulose hydrolysed more easily than cellulose. Dehydration reactions occur naturally during thermal treatments of polysaccharides, causing a decomposition of hydrolysed sugars (Fengel and Wegener, 1989). Pyranosidic ring structures will be dehydrated into hydroxymethylfurfural and furanosidic ring structures in furfural (Bobleter and Binder, 1980).

According to Abatzoglou et al. (1990), hemicellulose are easy to hydrolysed at high temperatures between 200 to $230^{\circ} \mathrm{C}$ even without the presence of an acid catalyst because of its structure and characteristics for example non-crystalline, highly disordered and heteropolymers (Ishii and Shimizu, 2001).

Boonstra and Tjeerdsma (2005), stated that the heat treatment at $180^{\circ} \mathrm{C}$ are less effective to depolymerise of hemicellulose however depolymerisation increased after temperature was raised to $185^{\circ} \mathrm{C}$ consequent degraded of hemicellulose content.

According to Tjeerdsma and Militz (2005), during thermal treatment carbonic acids mainly acetic acid will be formed as a result of cleavage of the acetyl groups of particular hemicelluloses (Bourgois and Guyonnet, 1988). Depending the on acid concentration and temperature applied, hemicellulose as the most reactive wood component will be hydrolysed into oligomeric and monomeric structures (Carrasco and Roy, 1992).

According to Garrote et al. (1999), depending on the conditions, polysaccharides (mainly hemicelluloses) are depolymerized to oligomers and monomers and the correspondent sugars (pentoses and hexoses) can be dehydrated to furfural and hydroxymethylfurfural, respectively.

Boonstra and Tjeerdsma (2005), indicated a depolymerization of carbohydrate mainly of the hemicellulose at higher temperature during hydro-thermolysis at the same time effect on the concentration of the soluble fraction because of the formation of furfural and some degradation of the lignin wood component.

Fengel and Wegener (1989), investigated that the acidic hydrolysis of hemicellulosic polysaccharides in wood is mainly a matter of breaking the glucosidic bonds $(1 \rightarrow 4)$ between monosaccharide units of the chain, the liberation of ester-bonded side groups such O-acetyl and the breaking of other ether-bonded side groups such as $\alpha$-D-galactopyranose. This will lower the molecular size such as reduce the degree of polymerization for the polysaccharide and fragments of low molecular by products such as mono- and disaccharides will be solubilized.

\subsubsection{Cellulose content}

The cellulose content of heated and unheated bamboo is presented in Table 1. The reduction of cellulose from treatment at $140^{\circ} \mathrm{C} / 60 \mathrm{~min}$ to $180^{\circ} \mathrm{C} / 30 \mathrm{~min}$ was $2.9 \%$ to $3.8 \%$ respectively compared to control. This reduction further increased to $5.1 \%$ at $180^{\circ} \mathrm{C} / 60 \mathrm{~min}$ and $14.1 \%$ at $220^{\circ} \mathrm{C} / 60 \mathrm{~min}$. This result shows that the degradation of bamboo cellulose increased when temperature and time of treatment increases.

Bamboo cellulose is considered to have major influence of bamboo strength. The bamboo cellulose structure is changed and that amorphous part can be degraded close to and above $220^{\circ} \mathrm{C}$. The amorphous part of the bamboo cellulose possibly hydrolyzed first, leaving a residue of cellulose with reduced degree of polymerisation and increased crystallinity. 
In a study of thermal treatment, degree of polymerisation of cellulose reduced and leveled of to values around 600 to 800 (Roffael and Schaller, 1971). Cellulose degradation can contribute to the loss of mechanical strength in wood under high temperature treatment (Sundqvist, 2004). Changes in the cellulose of wood during thermal have also been known as increase in crystallinity (Bhuiyan et al., 2000; Kubojima et al., 2001; Sivonen et al., 2002). Organic acids such as formic and acetic acid are liberated during the process which may affect the properties of wood (Risholm-Sundman et al., 1998; Garrote et al., 2001; Manninen et al., 2002).

Rubio et al. (1994), reported that cellulose degradation reactions started at an above $210-220^{\circ} \mathrm{C}$ and degree of degradation in the same way cellulose was significantly affected at temperature more than $270^{\circ} \mathrm{C}$ (Biermann et al., 1984). Different process conditions and treatment time applied during heat treatment may influence degradation rate of cellulose content (Boonstra and Tjeerdsma, 2005). Boonstra and Tjeerdsma, 2005 suggested that in hydrothermolysis treatment, (at $165-185^{\circ} \mathrm{C}$ ), an effective treatment time of 30 minutes while in curing treatment, (at $170-180^{\circ} \mathrm{C}$ ), an effective treatment time of 4 hours).

In hydrothermal at high temperatures, the heating time can be reasonably elongated in contrast with the duration of the isothermal reaction. This is important to a substantial hemicelullose alteration during heating (Carrasco \& Roy, 1992).

\subsubsection{Lignin content}

The lignin content of bamboo that had been heat treated in a palm oil is displayed in Table 1. There is no specific trend of lignin when treated at different treatment conditions. From Table 1, it shows that lignin content decreased at treatment temperature $140^{\circ} \mathrm{C}-180^{\circ} \mathrm{C}$ however, it increased when the treatment temperature was raised to $220^{\circ} \mathrm{C}$. At $180^{\circ} \mathrm{C}$, lignin content was higher when it was heated longer. A higher lignin found in the treated bamboo compared to the control indicates that the degradation of some hemicelluloses. Furthermore, changes in structure of bamboo lignin (plasticization) at high temperature were probably attributed to the increment of lignin content.

Kamden et al. (2002), found that increases in lignin content can be attributed to the loss of hemicellulose or fragile pentoses and hexoses during the heat treatment. They also initiated that increase in lignin content does not involve the formation of lignin during the process but the reduction of other wood components. Boonstra and Tjeerdsma (2005), found a similar trend of lignin content during treatment process in Picea abies, Pinus sylvestris and Pinus radiate D. They also observed that the lignin content of heat-treated wood is increased mainly due to depolymerisation of the carbohydrates. Polycondensation reactions result in a further cross-linking of the lignin network also contributes to increase of the lignin content. The reduction of water adsorption favours the effect of increased cross-linking of the lignin network while the proportion of free hydroxyl groups still available after heat treatment.

Tjeerdsma et al. (1998); Boonstra and Tjeerdsma (2005), stated that the condensation reactions of lignin at $185^{\circ} \mathrm{C}$, was probably contributed to higher lignin content and more hemicelluloses cleavage products.

According to Westermark et al. (1995), the changes in the lignin structure starts at temperature around $120^{\circ} \mathrm{C}$ in which the changes increased with the temperature. Kishimoto and Sano (2002), stated that lignin condensation was probably due to homolytic cleavage of ether bonds and subsequent rearrangement reactions. At temperature around $180^{\circ} \mathrm{C}$, homolytic cleavage of $\beta$-ether linkages and formation of radicals condensation products and possible cross links between lignin and polysaccharides (Tjeerdsma et al., 1998b; Kosikova et al., 1999; Sivonen et al., 2002). Lai (1991), observed that mild acidic hydrolysis of lignin is proposed to be the result of the breaking of cyclic $\alpha$-aryl ether bonds giving various lignin fragments such as lignols. Above $200^{\circ} \mathrm{C}$ the lignin degradation rate and the concentration of radicals that is formed are reported to strongly increase (Sivonen et al., 2001).

Boonstra and Tjeerdsma (2005), reported a depolymerization of carbohydrate mainly of the hemicellulose at higher temperature during hydro-thermolysis at the same time effect on the concentration of the soluble fraction because of the formation of furfural and some degradation of the lignin wood component. They also reported that heat treatment at higher temperatures $\left(185^{\circ} \mathrm{C}\right)$ result instead in a further decrease of water adsorption, in which decrease in free hydroxyl groups.

Tjeerdsma and Militz (2005), stated that lignin is the least reactive wood component, but at high temperatures, bonds within the lignin complex will be cleaved, resulting in a higher concentration of phenolic groups (Kolmann and Fengel, 1965). This state of increased reactivity of the lignin exposes the occurrence of various condensation reactions of aldehydes and autocondensation of lignin.

According to Kamdem et al. (2002), the chemical degradation of wood occurs in the order of hemicellulose, cellulose and lignin. A limited decomposition of lignin is observed at a temperature as low as $220^{\circ} \mathrm{C}$ with the presence of phenolic substances such as vanillin, coniferaldehyde and syringyl aldehyde (Sandermann and Augustin, 1964).

A partial depolymerization reported at $135^{\circ} \mathrm{C}$ for beech (Kosikova et al., 1999) in addition, splitting of $\beta$-aryl ethers and formation of lignin condensation products at $100^{\circ}-120^{\circ} \mathrm{C}$ was found for maple and hemolytic cleavage of phenolic $\beta$-aryl ether in wood lignin was found $130^{\circ} \mathrm{C}$ (Westermark et al., 1995). At temperature of $150^{\circ}-250^{\circ} \mathrm{C}$, major changes 
in the wood components occur. Both degradation and modification which thermal treatment in model systems was four times higher for hemicelulose than for cellulose and that the degradation rate for lignin was only half of that for cellulose at $150^{\circ} \mathrm{C}$ (Stamm, 1956).

\subsubsection{Starch content}

The mean starch content value in the bamboo culms is shown in Table 1. The starch content of heat-treated bamboo did not differ significantly between control and treatment conditions of $140^{\circ} \mathrm{C} / 60 \mathrm{~min}$. At $180^{\circ} \mathrm{C} / 30 \mathrm{~min}$ the starch content was reduced by $22 \%$ to $3.2 \%$, whilst at $180^{\circ} \mathrm{C} / 60 \mathrm{~min}$, it was reduced by $34 \%$ to $2.7 \%$. A high reduction of starch content was demonstrated at $220^{\circ} \mathrm{C} / 60 \mathrm{~min}$. The value was reduced by $54 \%$ to $1.9 \%$. The reduction of starch may probably hydrolysis of this component during heating. Removal starch from bamboo can improves the durability since fungus or pest depends on starch as a favourite food to survive.

Sundqvist, 2004 reported that pectin and starch has a similar molecular structure such as hemicellulose. He also stated that at $200^{\circ} \mathrm{C}$, starch become hydrolysed under this conditions same with hemicellulose.

\section{Conclusion}

Holocellulose content of boil-treated bamboo did not differ to each other when it was heated at $180^{\circ} \mathrm{C}$ however, the content reduced significantly when treated at $220^{\circ} \mathrm{C} / 60 \mathrm{~min}$. Hemicellulose content of bamboo was not affected by the treatments. Cellulose content in bamboo was only reduced when it was treated at temperature higher than $180^{\circ} \mathrm{C}$. At $140^{\circ} \mathrm{C}$ to $180^{\circ} \mathrm{C}$, the lignin content in the treated bamboo decreased, but the chemical content value increased when the bamboo was heated at $220^{\circ} \mathrm{C}$. Starch content in the bamboo was found to be inversely proportional to treatment temperatures. At $180^{\circ} \mathrm{C}$, duration of treatment did not significantly affect the starch content. The results indicated that degradation of cellulose and hemicellulose of heat-treated bamboo at higher temperature and time was attributed to plasticization of lignin during heating in the same time hydrolysed the starch content.

\section{References}

Abd. Latif, M. and Wan Tameze, W.A., (1990). Anatomical Properties and Mechanical Reationship of Some Natural Stand Malaysia Bamboo. Paper Presented at IUFRO XIX World Congress held in Motral, Canada, 5-12 August 1990.

Anonymous, (1974). Technical Association of the Pulp and Paper Industry: (TAPPI Standard T222 os-74) Atlanta, USA.

Anonymous, (1988). Technical Association of the Pulp and Paper Industry: (TAPPI Standard T204 om-88) Atlanta, USA.

Anonymous, (1993). Technical Association of the Pulp and Paper Industry: (TAPPI Standard T203 om-93) Atlanta, USA.

Bhuiyan, M.T.R., and Hirai, N. and Sobue, N. (2000). Changes of crystallinity in wood cellulose by heat treatment under dried and moist conditions. Journal of Wood Science. Vol. 46:431-436.

Biermann, C.J., Schultz, T.P. and McGinnis, G.D. (1984). Rapid steam hydrolysis/ extraction of mixed hardwoods as a biomass pretreatment. J. Wood Chem. Technol. 4: 111-128.

Bobleter, O., Binder, H. (1980). Dynamischer hydrothermaler Abbau von Holz. Holzforschung 34:48-51.

Abatzoglou, N., Koeberle, P.G., Chornet, E., Overend, R.P. and Koukios, E.G. (1990). An application to medium consistency suspension of hardwoods using a plug flow reactor. Can J Chem Eng 68:627-638

Boonstra, M.J. and Tjeerdsma, B. (2005). Chemical analysis of heat treated softwoods. Journal of Holz als Roh-und Wekstoff. DOI 10.1007/s001007-005-0078-4.

Bourgois, P.J. and Guyonnet, R., (1988). Characterization and analysis of torrefied wood. Wood science and Technology: Vol. 22, 143-155.

Carrasco, F. and Roy, C., (1992). Kinetic study of dilute-acid prehydrolysis of xylan containing biomass. Wood Sci Technol 26:189-208.

Fengel, D. and Wegener, G. (1984). Wood: Chemistry, ultrastructure and reactions. Walter de Gruyter \& Co, Berlin.

Garrote, G., Dominguez, H. and Parajo, J.C., (1999). Hydrothermal processing of lignocellulosic materials. Journal of Holz als Roh-und Wekstoff. Vol 57: 191-202. Springer-Verlag.

Garrote, G., Dominguez, H. and Parajo, J.C. (2001). Study on the deacetylation of hemicelluloses during the hydrothermal processing of Eucalyptus wood. Holz als Roh-und Werkstoff. Vol. 59:53-59.

Humprey, F.R. and Kelly, J. (1960). “A Method for the Determination of Starch”. Wood Analytical Chemistry Acta. 24: 66-70. 
Ishii, T. and Shimizu, K. (2001). Chemistry of cell wall polysaccharides. In: Hon DN-S, Shiraishi N (eds) Wood and cellulosic chemistry. Marcel Dekker Inc, New York, Chapter 8, pp 175-212.

Jamaluddin, K, (1999). Properties of Particleboard and Particle-Filled Thermoplastic Composite from Bamboo (Gigantochloa Scortechinii). PhD. Thesis. Universiti Putra Malaysia, Malaysia.

Kamden, D.P., Pizzi, A. and Jermannaud, A., (2002). Durability of heat-treated wood. Journal of Holz als Roh-und Wekstoff. Vol 60: 1-6. DOI 10.1007/s001007-001-0261-1.

Kishimoto, T. and Sano, Y., (2002). Delignification mechanism during high-boiling solvent pulping. Part 2. Homolysis of Guaiacylglcerol- $\beta$-guaiacyl ether. Holzforschung: Vol. 56:623-631.

Kollman, F. and Fengel, D.,(1965). Changes in the chemical composition of wood by thermal treatment. Holz als Rohund Werkstoff: Vol. 23, 461-468.

Kosikova, B., Hricovini, M. and Cosetino, C., (1999). Interaction of lignin and polysaccharides in beech wood (Fagus sylvatica) during drying processes. Wood Science and Technology: Vol. 33, 373-380.

Kubojima, Y., Okano, T. and Ohta, M. (2000). Bending strength and toughness of heat-treated wood. Journal of Wood Science. Vol. 46:8-15.

Lai, Y.Z. (1991). Chemical degradation In: Wood and Cellulosic Chemistry. Eds. Hon, D.N.S. and Shiraishi, N., Marcel Dekker, Inc., New York. Pp. 455-524.

Leithoff, H. and Peek, R.D., (1997). Heat treatment of timber. A Brief Literature Survey. In Proceeding of the COST Action E2: Wood Durability, Improvement of Chemicals and Substrate Modification, Dublin, 19-21.3.1997. Brussels: European Commission, 1997.

Liese, W. (1985). Bamboos - Biology, Silvics, Properties, Utilisation. Schriftenreihe der GTZ, No.180.

Liese, W. and Kumar, S. (2003). Bamboo Preservation Compendium. Technical Report 1 (INBAR Technical Report 22).

Manninen, A.M., Passanen, P. and Holopainen, J.K. (2002). Comparing the VOC emissions between air-dried and heat-treated Scots pine wood. Atmospheric Environment, Elsevier Science Ltd. Vol. 36:1763-1768.

Risholm-Sundman, M., Lundgren, M., Vestin, E. and Herder, P. (1998). Emissions of acetic acids and other volatile organic compounds from different species of solid wood. Holz als Roh-und Werkstoff. Vol. 56:125-129.

Roffael, E. and Schaller, K. (1971). The influence of thermal treatment on cellulose. Holz als Roh-und Werkstoff. Vol. 29:275-278.

Rubio, M., Tortosa, J.F., Gomez, D., Minana, A. and Soler, A. (1994). El fraccionamiento de los materiales vegetales mediante procesos combinados de autohidroÂlisis-organosolvolisis. Afnidad. 51: 95-102.

Ruyter, H.P. (1989). Treatment of biomass with steam. Shell into research. 89-203170.9. EP0187422

Sandermann, W. and Augustin, H. (1964). Chemical investigation on the thermal decomposition of wood-Part III: Chemical investigation on the course of decomposition. Holz als Roh-und Werkstoff 22(10):377-378.

Sivonen, H., Maunu, S.L., Sundholm, F., Jamsa, S. and Viitaniemi, P., (2001). CCPMAS NMR studies of thermally modified wood. International Symposium on Wood and Pulping Chemistry, Nice, France. 3:591-594

Sivonen, H., Maunu, S.L., Sundholm, F., Jamsa, S. and Viitaniemi, P., (2002). Magnetic resonance studies of thermally modified wood. Holzforschung: Vol. 56, 648-654.

Stamm, A.J., (1956). Thermal degradation of wood and cellulose. Journal of industrial and engineering chemistry:Vol. 48, 413-417.

Sundqvist, B., (2004). Colour Changes and Acid Formation in Wood During Heating. Ph.D. thesis. Lulea University of Technology.

Thammicha, S., (1989). Bamboo. Pages 3:1-11 in A.V. Bassili and W.G. Davies, eds. A Workshop and Design and Manufacturing of Bamboo and Rattan Furniture held in Jakarta, Indonesia, March 3-14, 1989. Kuala Lumpur: Food and Agriculture Organization.

Tjeerdsma, B.F., Boonstra, M. and Militz, H. (1998). Thermal modification of non-durable wood species. 2. Improved wood properties of thermally treated wood. International Research Group on Wood Preservation, Document no. IRG/WP 98-40124.

Tjeerdsma, B.F. and Militz, H., (2005). Chemical changes in hydrothermal treated wood: FTIR analysis of combined hydrothermal and dry heat-treated wood. Journal of Holz als Roh-und Wekstoff. Vol 63: 102-111. DOI 10.1007/s001007-005-0063-y 
Westermark, U., Samuelsson, B. and Lundqvist, K. (1995). Homolytic cleavage of the $\beta$-ether bond in phenolic $\beta$-o-4 structures in wood lignin and guaiacylglycerol- $\beta$-guaiacyl ether. Research on Chemical Intermediates. VSP International Science Publication, Netherlands. 21:343.

Table 1. Mean chemical analyses of 3-years-old G. scortechinii culm after heating in palm oil at varies temperatures and times

\begin{tabular}{|c|c|c|c|c|c|c|}
\hline $\begin{array}{l}\text { Heating } \\
\text { conditions }\end{array}$ & $\mathrm{N}$ & $\begin{array}{c}\text { Holo- } \\
\text { cellulose } \\
(\%)\end{array}$ & $\begin{array}{c}\text { Hemi-cellulo } \\
\text { se } \\
(\%)\end{array}$ & $\begin{array}{c}\text { Cellulose } \\
(\%)\end{array}$ & $\begin{array}{c}\text { Lignin } \\
(\%)\end{array}$ & $\begin{array}{c}\text { Starch } \\
(\%)\end{array}$ \\
\hline Control & 6 & $\begin{array}{l}81.4^{\mathrm{a}} \\
(3.69)\end{array}$ & $\begin{array}{l}26.2^{\mathrm{a}} \\
(3.58)\end{array}$ & $\begin{array}{l}55.2^{\mathrm{a}} \\
(1.75)\end{array}$ & $\begin{array}{l}22.3^{a b} \\
(3.31)\end{array}$ & $\begin{array}{l}4.1^{\mathrm{a}} \\
(0.18)\end{array}$ \\
\hline $140^{\circ} \mathrm{C} / 60$ & 6 & $\begin{array}{c}81.4^{\mathrm{a}} \\
(4.54) \\
\{0\}\end{array}$ & $\begin{array}{l}27.8^{a} \\
(27.8) \\
\{6.21\}\end{array}$ & $\begin{array}{l}53.6^{\mathrm{ab}} \\
(2.01) \\
\{-2.9\}\end{array}$ & $\begin{array}{l}21.1^{\mathrm{b}} \\
(4.09) \\
\{-5.4\}\end{array}$ & $\begin{array}{c}4.0^{\mathrm{a}} \\
(0.32) \\
\{-2\}\end{array}$ \\
\hline $180^{\circ} \mathrm{C} / 30$ & 6 & $\begin{array}{l}79.7^{\mathrm{a}} \\
(5.15) \\
\{-2.1\}\end{array}$ & $\begin{array}{l}26.6^{\mathrm{a}} \\
(4.96) \\
\{1.42\}\end{array}$ & $\begin{array}{l}53.1^{\mathrm{ab}} \\
(0.71) \\
\{-3.8\}\end{array}$ & $\begin{array}{l}21.6^{b} \\
(2.98) \\
\{-3.1\}\end{array}$ & $\begin{array}{l}3.2^{b} \\
(0.35) \\
\{-22\}\end{array}$ \\
\hline $180^{\circ} \mathrm{C} / 60$ & 6 & $\begin{array}{c}76.5^{a b} \\
(3.36) \\
\{-6\}\end{array}$ & $\begin{array}{l}24.1^{\mathrm{a}} \\
(2.14) \\
\{-7.98\}\end{array}$ & $\begin{array}{l}52.4^{b} \\
(3.11) \\
\{-5.1\}\end{array}$ & $\begin{array}{l}22.0 \text { ab } \\
(3.01) \\
\{-1.3\}\end{array}$ & $\begin{array}{l}2.8^{b} \\
(0.42) \\
\{-34\}\end{array}$ \\
\hline $220^{\circ} \mathrm{C} / 60$ & 6 & $\begin{array}{l}72.7^{b} \\
(6.07) \\
\{-10.7\}\end{array}$ & $\begin{array}{l}25.3^{a} \\
(6.26) \\
\{-3.63\}\end{array}$ & $\begin{array}{l}47.4^{c} \\
(2.51) \\
\{-14.1\}\end{array}$ & $\begin{array}{l}26.0^{a} \\
(3.94) \\
\{16.6\}\end{array}$ & $\begin{array}{l}1.9^{\mathrm{c}} \\
(0.20) \\
\{-54\}\end{array}$ \\
\hline
\end{tabular}

Note: Values in parentheses are standard deviations

Means with the same letter are not significantly different $(\mathrm{p}<0.05)$

$\{\quad\}=\%$ change from control

$\mathrm{N}=$ number of sample 